\title{
Effects of Polyadenylation Inhibition on Meiosis Progression in Relation to the Polyadenylation Status of Cyclins A2 and B1 During In Vitro Maturation of Bovine Oocytes
}

\author{
JUAN M. TRAVERSO,* ISABELLE DONNAY, AND ANNE-SOPHIE LEQUARRE \\ Veterinary Unit, Institut des Sciences de la Vie, Université Catholique de Louvain, Louvain-la-Neuve, Belgium
}

\begin{abstract}
The control of protein synthesis during maturation in oocytes is mainly exerted through cytoplasmic polyadenylation of stored mRNAs. We first analyzed the polyadenylation status of cyclins $A 2$ and B1 during in vitro maturation (IVM) of bovine oocytes, using Rapid Amplification of cDNA Ends-Polyadenylation Technique (RACE-PAT). An inconstant elongation of the poly $(A)$ tail was observed for cyclin A2 transcripts after maturation, while a constant lengthening was observed for cyclin B1, occurring during the first $12 \mathrm{hr}$ of incubation. We then evaluated the effects of the polyadenylation inhibitor $3^{\prime}$-deoxyadenosine (3'$d A$ ), on polyadenylation and nuclear maturation. The presence of $0.02 \mathrm{mM} 3^{\prime}$-dA during the whole incubation period or from $6 \mathrm{hr}$ after its beginning completely prevented meiosis progression in $100 \%$ of the oocytes. Polyadenylation of cyclin B1 was also completely prevented when $3^{\prime}-\mathrm{dA}$ was added at $0 \mathrm{hr}$, and greatly reduced when added at $6 \mathrm{hr}$. When $3^{\prime}-\mathrm{dA}$ was added at $12 \mathrm{hr}$, around metaphase I (MI), 46.9\% of the oocytes have reached metaphase $\mathrm{II}$ (MII, vs. $78.8 \%$ in the control group) at $24 \mathrm{hr}$. The use of the same concentration of $3^{\prime}$-deoxyguanosine $\left(3^{\prime}-d G\right)$, that impairs transcription but not polyadenylation, did not affect cyclins polyadenylation, nor nuclear maturation, whatever was the timing of addition. These results suggest that the polyadenylation of cyclin $\mathrm{B} 1$ could be related to the first peak of activity of MPF, occurring around MI (10-12 hr after the onset of the maturation period). They also show that, in our culture conditions, inhibition of polyadenylation prevents meiosis progression, especially up to the MI stage, while inhibition of transcription does not. Mol. Reprod. Dev. 71: 107-114, 2005. () 2005 Wiley-Liss, Inc.
\end{abstract}

Key Words: IVM; cytoplasmic polyadenylation; bovine oocyte; meiosis progression

\section{INTRODUCTION}

Mammalian oocytes are arrested in late G2 of the first meiotic division, at the germinal vesicle (GV) stage. These oocytes will resume meiosis, either naturally after hormonal stimulation (LH surge), or if released from the inhibitory influence of the follicular environment, as in the case of in vitro cultures (Pincus and Enzmann, 1935; Smith, 1989).

Events taking place during in vitro oocyte maturation can be distinguished as occurring at the nuclear or cytoplasmic level. The first evident event of nuclear maturation is chromatin condensation, followed by the germinal vesicle breakdown (GVBD). Meiosis then continues with completion of the first meiotic division, extrusion of the first polar body, and the oocyte's arrest at metaphase of the second meiotic division (MII). At the cytoplasmic level, numerous mRNA molecules and proteins are stored during the growth phase that precedes maturation. The stockpile of mRNAs will allow protein synthesis in the maturing oocyte and early embryo while transcription is maintained at very low levels, a period that in the bovine species spans from GVBD up to the 9/16-cell stage embryo (Memili and First, 1999, 2000). At the 9/16-cell stage, the embryo genome becomes fully functional and gene expression no longer depends mostly on transcripts of maternal origin.

During this transcriptionally-almost-silent period, gene expression control is exerted at the post-transcriptional level mainly by cytoplasmic polyadenylation (reviewed by Richter, 1999; de Moor and Richter, 2001; Macdonald, 2001; Mangus et al., 2003). It has been demonstrated that such control involves the action of various factors on specific sequences found in the $3^{\prime}$ untranslated region ( $3^{\prime}$-UTR) of certain transcripts.

Amongst those sequences, the most important ones are AAUAAA, known as nuclear polyadenylation element (NPE), and the cytoplasmic polyadenylation element (CPE), a UUUUUAU consensus motif that is generally found immersed in a U-rich region around 20 30 nucleotides upstream of the NPE (Fox et al., 1989; McGrew et al., 1989). Cytoplasmic polyadenylation

Grant sponsor: European Commission (grant EU); Grant number: QLK3-CT1999-00104; Grant sponsor: Fonds Spécial de la Recherche (Belgium).

*Correspondence to: Juan M. Traverso, Unité des Sciences Vétérinaires, Université Catholique de Louvain, Place Croix du sud 5 bte 10, B-1348 Louvain-la-Neuve, Belgium.

E-mail: traverso@vete.ucl.ac.be

Received 5 July 2004; Accepted 14 October 2004

Published online in Wiley InterScience (www.interscience.wiley.com). DOI $10.1002 / \mathrm{mrd} .20247$ 
allows a fine and precise control of the translation of many of the mRNAs stored in the cytoplasm. Amongst those mRNAs we can mention genes that play a key role in the resumption and control of the meiotic process or in pre-implantation development, as it has been described for c-mos, cyclins, and cdks in Xenopus laevis (Sheets et al., 1995; Stebbins-Boaz et al., 1996; de Moor and Richter, 1997; Barkoff et al., 1998; reviewed by Richter, 1999), and c-mos and cyclin B1 in mouse (Gebauer et al., 1994; Gebauer and Richter, 1996; Tay et al., 2000).

The meiotic process is mainly controlled by the activities of both the mitogen activated protein kinase (MAPK) and the maturation promoting factor (MPF). MPF is a heterodimer formed between cyclin B1, which is the regulatory component, and p34 ${ }^{\mathrm{cdc} 2}$ kinase, also known as cyclin-dependent kinase 1 (cdk1), which encloses the catalytic domain. MPF is the key regulator of meiotic resumption in oocytes (Wasserman and Masui, 1976), and its activity is regulated by phosphorylation/ dephosphorylation in Thr-14 and Tyr-15 of cdk1, respectively carried out by the wee1/Myt1 kinases and the cdc25 phosphatase (reviewed by Morgan, 1995; Yamashita et al., 2000). In the bovine species, the need of polyadenylation for MPF activation has been reported (Krischek and Meinecke, 2002), as well as the relationship between polyadenylation status and oocyte developmental competence, and its evolution between oocyte maturation and first embryonic cleavage (BreviniGandolfi et al., 1999; Brevini et al., 2002). Previous work also showed the changes in the levels of cyclin B2 protein during oocyte maturation (Wu et al., 1997), and the changes in the levels of cyclin B1 protein (Levesque and Sirard, 1996) and mRNA (Robert et al., 2002). Cyclin A presents two subtypes in mammals, namely A1 and A2. Cyclin A2 controls the progression through S phase and the entry into M phase (Pagano et al., 1992; Loyer et al., 1994), and is essential for development in mouse, the null genotype being lethal, as it was proven in vivo using a targeted deletion strategy against the A2 gene. Nevertheless, embryos lacking the cyclin A2 gene can develop until the stage of implantation at around day 5.5 post coitum (Murphy et al., 1997).

In the bovine species, the presence of cyclin A2 mRNA has recently been detected in immature and mature oocytes, both in vitro and in vivo (Lonergan et al., 2003), however, to our knowledge there is no information about the polyadenylation status of cyclin A2 transcript in bovine oocytes during in vitro maturation (IVM).

One of the goals of this work was to analyze the poly(A) tail length of cyclins B1 and A2 during IVM in bovine oocytes. For doing so, we used Rapid Amplification of cDNA Ends-Poly(A) Test (RACE-PAT), a method described by Salles and Strickland (1995); Salles et al. (1999). This technique was chosen instead of oligo(dT)/ RNase H-Northern, the classical polyadenylation assay, as it is much more sensitive. We combined the RACEPAT analysis with the use of $3^{\prime}$-deoxyadenosine $\left(3^{\prime}\right.$-dA), a strong inhibitor of polyadenylation, and $3^{\prime}$-deoxyguanosine $\left(3^{\prime}-\mathrm{dG}\right)$ as a control. When $3^{\prime}-\mathrm{dA}$ is added to the maturation medium, it is metabolized in the oocyte to $3^{\prime}$ dATP, and incorporated into growing nucleotide chains and poly (A) tails during polyadenylation. Once $3^{\prime}-\mathrm{dA}$ is added to the poly(A) tail, further addition of adenosine is prevented because of the lack of a hydroxyl group (Siev et al., 1969; Nakazato et al., 1974; Kuge and Inoue, 1992). The use of $3^{\prime}-\mathrm{dG}$ allowed us to discriminate between polyadenylation inhibition (exerted by $3^{\prime}-\mathrm{dA}$ ) and transcription inhibition (due to both $3^{\prime}-\mathrm{dA}$ and $3^{\prime}-\mathrm{dG}$ ).

The impact of adenylation inhibition on nuclear maturation was also analyzed, at different times during the maturation period.

\section{MATERIALS AND METHODS Collection of Oocytes and IVM}

Ovaries were collected at a local slaughterhouse and transported to the laboratory at room temperature $\left(>20^{\circ} \mathrm{C}\right)$. Cumulus-oocyte complexes (COCs) were aspirated from follicles ranging from 3 to $8 \mathrm{~mm}$ in diameter, and only good quality COCs (dark homogeneously granulated cytoplasm surrounded by three or more compact layers of cumulus cells) were selected. Groups of 20-70 COCs were placed into four-well multidishes (Nunc, Roskilde, Denmark) and matured under $20 \% \mathrm{O}_{2}$ and $5 \% \mathrm{CO}_{2}$ in tissue culture medium 199 (TCM-199; Gibco, Paisley, Scotland), supplemented with $10 \mathrm{ng} / \mathrm{ml}$ epidermal growth factor (EGF; Sigma, Steinheim, Germany) and $0.4 \mathrm{mM}$ pyruvate, without serum. COCs were matured for the appropriate time depending on the experimental conditions.

\section{RNA Extraction}

COCs were carefully denuded by repeated pipetting and washed three times in TCM-199. The absence of remaining cumulus cells attached to the oocytes was verified by Hoechst staining. Pools of 20 oocytes were made for each sample, and stored at $-80^{\circ} \mathrm{C}$ in a minimum volume of medium. Total RNA from each pool was extracted in $100 \mu \mathrm{l}$ of Tripur (Roche Molecular Biochemicals, Indianapolis, IN) following specifications of the manufacturer, and $20 \mu \mathrm{g}$ of glycogen (Glycoblue; Ambion, Austin) added as a carrier. After precipitation in isopropanol, samples were centrifugated at $12,000 \mathrm{~g}$ and pellets washed in ethanol $70 \%$, vacuum-dried, and resuspended in RNAse-free water.

\section{Determination of Nuclear Maturation}

Oocytes were denuded and rinsed as already described, and fixed overnight in ethanol $96 \%$ on a microscope slide to assess the nuclear maturation status. Fixed oocytes were stained with $10 \mu \mathrm{g} / \mathrm{ml}$ of Hoechst 33342 (bisbenzimide; Calbiochem, Darmstadt, Germany) diluted in $2.3 \%$ tri-sodium citrate buffer. Oocytes were examined under a Nikon fluorescence microscope (excitation wavelength: 330-380 nm, barrier filter at $420 \mathrm{~nm}$ ), and classified as metapase II (MII, presenting a metaphasic plate and a polar body), metaphase I (MI, presenting a metaphasic plate, but no polar body), and stages before MI. 


\section{RACE-PAT}

Changes in the poly(A) tail length were studied using RACE-PAT, a modification of the RACE protocol.

\section{Reverse Transcription (RT)}

Total extracted RNA was reverse-transcribed as described by Salles and Strickland (1995), with minor modifications. Reactives were purchased from Invitrogen (Carlsbad, NM), unless otherwise specified.

Briefly, RNA was denatured at $65^{\circ} \mathrm{C}$ during 5 min in a final volume of $6 \mu \mathrm{l}$, with $1 \mu \mathrm{l}(200 \mathrm{ng} / \mu \mathrm{l})$ of oligo(dT) anchor (5'-GCGAGCTCCGCGGCCGCGT $12^{-} 3^{\prime}$ ), and transferred to a water bath at $42^{\circ} \mathrm{C}$. Then $14 \mu \mathrm{l}$ of a mixture were added, containing $4 \mu \mathrm{l}$ of $5 \times$ SuperScript ${ }^{\mathrm{TM}}$ III Rnase $\mathrm{H}$ reverse transcriptase buffer (250 mM Tris-HCl, $375 \mathrm{mM} \mathrm{KCl}, 15 \mathrm{mM} \mathrm{MgCl})_{2}$ ), $1 \mu \mathrm{l}$ (40 U/ $\mu \mathrm{l}$ ) Rnase inhibitor (Amersham Pharmacia, Uppsala, Sweden), $2 \mu \mathrm{l}$ 0.1M DTT, $1 \mu \mathrm{l} 10 \mathrm{mM}$ dNTPs (Roche, Mannheim, Germany), $2 \mu \mathrm{l}$ (400 U) SuperScript ${ }^{\mathrm{TM}}$ III Rnase H RT, and $4 \mu \mathrm{l}$ of RNase-free water. Samples were reverse transcribed at $42^{\circ} \mathrm{C}$ for $1 \mathrm{hr}$, ending with a step of $15 \mathrm{~min}$ at $65^{\circ} \mathrm{C}$ for enzyme inactivation.

\section{PCR Amplification}

RT samples were PCR-amplified using the oligo(dT)anchor primer already described, and the following primers at the $5^{\prime}$ end: cyclin A2: $5^{\prime}$-TCAACCCACCAGAGACACTA-3' ${ }^{\prime}$, and cyclin B1: 5'-GGCTGTGGCAAAGGTGTAAC-3', at positions 1193 and 1389, respectively. Both $5^{\prime}$ primers hybridize in the $3^{\prime}$ UTR region of each analyzed transcript. Sequences for both cyclins were obtained from a NCBI database (accession numbers X68321 and L26548 for cyclin A2 and B1, respectively). The size of the amplified fragments from the upper primer location to the beginning of the poly(A) tail, length of the poly(A) tail varies upon conditions-is of $324 \mathrm{bp}$ for cyclin A2, and $165 \mathrm{bp}$ for cyclin B1. We have also used another $5^{\prime}$ primer for cyclin B1 (5'-ACCTGGCAAAGAATGTGGTC-3'), at position 1249 . Reactives were purchased from Qiagen (Leusden, The Netherlands), unless otherwise specified.

One microliter of RT product was amplified in a reaction mixture consisting of $2.5 \mu \mathrm{l}$ of $10 \times$ PCR Buffer (Tris- $\left.\mathrm{HCl}, \mathrm{KCl}\left(\mathrm{NH}_{4}\right)_{2} \mathrm{SO}_{4}, 15 \mathrm{mM} \mathrm{MgCl}\right)_{2}$ ), $5 \mu \mathrm{l}$ of Q solution, $0.5 \mu \mathrm{l}$ of $10 \mathrm{mM}$ dNTPs (Roche), $12.5 \mathrm{pmol}$ of oligo anchor primer, $12.5 \mathrm{pmol}$ of each $5^{\prime}$ primer, $1.5 \mathrm{U}$ of HotStarTaq $^{\mathrm{TM}}$ DNA polymerase, and $14.7 \mu \mathrm{l}$ of sterile water. PCR was carried out in a programmable thermal cycler (PTC-100, MJ Research, Inc., Watertown, MA), in the following conditions: $15 \mathrm{sec}$ at $95^{\circ} \mathrm{C}$ (activation of the enzyme), $30 \mathrm{sec}$ at $93^{\circ} \mathrm{C}$ (double strand denaturation temperature), $1 \mathrm{~min}$ at $59^{\circ} \mathrm{C}$ (annealing temperature), and $1 \mathrm{~min}$ at $72^{\circ} \mathrm{C}$ (double strand extension temperature), performing 31 cycles. Differences in the poly(A) tail length were observed as smears of proportional different lengths in a $4 \%$ agarose gel.

\section{Experimental Design}

\section{Experiment 1: Assessment of the poly(A) tail length and nuclear maturation status during IVM}

Assessment of poly(A) tail length before and after maturation. COCs were matured during $24 \mathrm{hr}$ as described above, and the length of the poly(A) tail analyzed in denuded oocytes by RACE-PAT before $(0 \mathrm{hr})$ and after maturation ( $24 \mathrm{hr}$ ). Groups of 25-30 denuded oocytes were fixed in parallel at the end of the maturation period, in order to assess their nuclear maturation status. This experiment was carried out nine times for cyclin A2 and five for cyclin B1.

Kinetics of the changes in the poly(A) tail for cyclin B1, and assessment of nuclear maturation status during maturation. With the aim of studying the timing of the changes in the poly(A) tail during the meiotic process, a kinetic study was carried out for cyclin B1. Maturation was stopped at 6,12, 18, and $24 \mathrm{hr}$ from the onset of the process, and the length of the poly(A) tail analyzed by RACE-PAT in denuded oocytes. In parallel, groups of 25-30 denuded oocytes were fixed for each time point, and the nuclear maturation status analyzed. This experiment was repeated two times.

Experiment 2: Inhibition of polyadenylation during IVM. Cordycepin $\left(3^{\prime}-\mathrm{dA}\right)$ and $\left(3^{\prime}-\mathrm{dG}\right)$ were used as specific inhibitor of polyadenylation and control, respectively. Both purines were purchased from Sigma (Steinheim, Germany).

Effects of $3^{\prime}-d A$ on poly(A) tail length and nuclear maturation status. In a preliminary experiment, different concentrations of $3^{\prime}-\mathrm{dA}$ and $3^{\prime}-\mathrm{dG}$ were tested, (2, $0.5,0.08,0.02$, and $0.01 \mathrm{mM}$ final concentration in the maturation medium). The $0.02 \mathrm{mM}$ concentration was chosen, as it was the lower concentration of $3^{\prime}-\mathrm{dA}$ that effectively inhibited polyadenylation. $3^{\prime}$-dG was used at the same concentration (data not shown).

COCs were matured during $24 \mathrm{hr}$ in the presence of $3^{\prime}-\mathrm{dA}$ or $3^{\prime}-\mathrm{dG}$, and the length of the smear obtained by RACE-PAT was analyzed in denuded immature $(0 \mathrm{hr})$ and mature $(24 \mathrm{hr})$ oocytes. Oocytes issued from COCs matured in normal conditions for the same period of time were used as control. Groups of 25-30 denuded oocytes from each condition were fixed at the end of the maturation period ( $24 \mathrm{hr}$ ), and the nuclear maturation status analyzed. The experiment was repeated three times.

Effects of the addition of $3^{\prime}-d A$ at different times during maturation. Cyclin B1 poly(A) tail length and nuclear maturation status. $3^{\prime}$-dA or $3^{\prime}$-dG were added to maturation medium at $0,6,12$, and $18 \mathrm{hr}$ from the beginning of the incubation period, to assess the effects of $3^{\prime}$-dA addition on nuclear maturation and polyadenylation, during the maturation process. The length of the smear obtained by RACE-PAT was analyzed in denuded oocytes at the end of maturation (24 hr). Groups of $25-$ 30 denuded oocytes for each time point were fixed at the end of the maturation period ( $24 \mathrm{hr}$ ), and the nuclear maturation status analyzed. The experiment was repeated twice. 
Study of the reversibility of the effect of $3^{\prime}-d A$ on nuclear maturation status. The aim of this experiment was to test the reversibility of the action of cordycepin on the prevention of meiosis resumption. COCs were incubated in maturation media containing $3^{\prime}$-dA or $3^{\prime}$ $\mathrm{dG}$ during 2,4 , and $6 \mathrm{hr}$, rinsed three times in TCM-199, and transferred to normal maturation medium until completing $24 \mathrm{hr}$ of maturation. Groups of 25-30 denuded oocytes for each condition were fixed in parallel at the end of the maturation period, and the nuclear maturation status analyzed as already described. The protocol was repeated three times.

\section{RESULTS}

\section{Experiment 1: Assessment of the Poly(A) Tail Length and Nuclear Maturation Status During IVM}

Assessment of poly(A) tail length before and after maturation

Cyclin A2. Immature oocytes presented a very short smear. Inconstant presence of a longer smear was observed after $24 \mathrm{hr}$ of maturation in roughly half (five out of nine) of the samples (Fig. 1). Taking this into account, cyclin A2 transcript was not further analyzed.

Cyclin B1. Immature oocytes present a short smear, that appears lengthened after $24 \mathrm{hr}$ of incubation in the maturation medium (Fig. 2). Similar results were obtained with the two different $5^{\prime}$ primers used. Representative results obtained with one of the primers (5'-GGCTGTGGCAAAGGTGTAAC-3') are shown.

Kinetics of the changes in the poly(A) tail for cyclin B1, and assessment of nuclear maturation status during maturation. An increase of the smear length was already observed at $6 \mathrm{hr}$, and a further increase was seen at $12 \mathrm{hr}$ from the beginning of the maturation period. No further changes in the smear length were observed at 18 and $24 \mathrm{hr}$ (Fig. 3).

Overall, an $80 \%$ maturation rate was observed after $24 \mathrm{hr}$ incubation. A large majority of the oocytes had

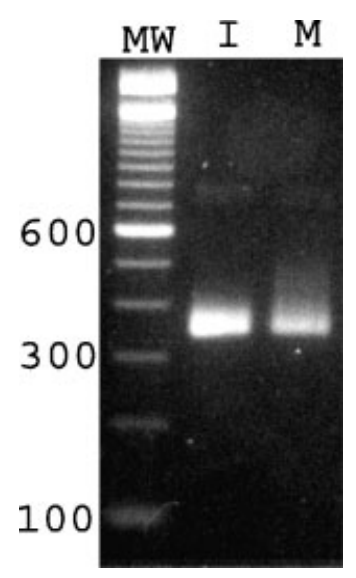

Fig. 1. RACE-PAT analysis in cyclin A2 transcript, before and after maturation. MW: molecular weight marker (bp); I: immature oocytes; M: mature oocytes.

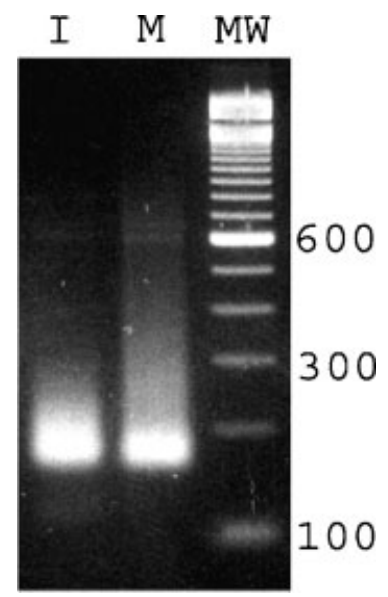

Fig. 2. RACE-PAT analysis in cyclin B1 transcript, before and after maturation. MW: molecular weight marker (bp); I: immature oocytes; M: mature oocytes.

reached the MII stage $18 \mathrm{hr}$ after the beginning of the maturation period (Table 1).

The MI stage was reached between 6 and $12 \mathrm{hr}$ of incubation.

\section{Experiment 2: Inhibition of Polyadenylation During IVM}

Effects of $3^{\prime}$-dA on poly(A) tail length and nuclear maturation status. When oocytes were matured during $24 \mathrm{hr}$ in the presence of $0.02 \mathrm{mM}$ $3^{\prime}-\mathrm{dA}$, no lengthening in the smear was observed at the end of the maturation period, and transcripts presented a smear of the same length as before maturation or even shorter. However, the group treated with $0.02 \mathrm{mM} 3^{\prime}-\mathrm{dG}$ showed a smear of the same length of the one observed in the control group matured in normal conditions (Fig. 4).

Moreover, $3^{\prime}$-dA completely blocks meiosis progression in treated oocytes: none of the oocytes reached the MI stage $(n=75)$. There were no significant differences in the maturation status between $3^{\prime}$-dG-treated $(\mathrm{n}=64)$

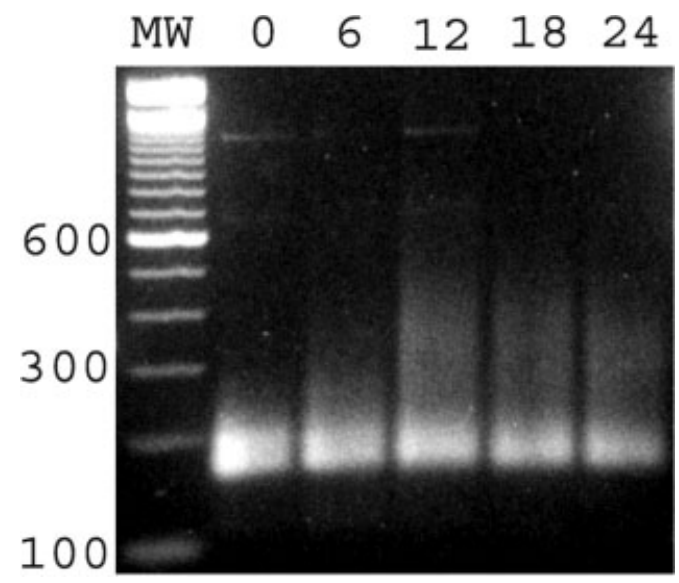

Fig. 3. RACE-PAT analysis in cyclin $B 1$ transcript, kinetics of maturation. MW: molecular weight marker (bp); 0-24: time (hr) from the onset of the maturation period. 
TABLE 1. Kinetics of Nuclear Maturation of In Vitro Matured COCs

\begin{tabular}{llccc}
\hline Time $(\mathrm{hr})$ & $\mathrm{N}$ & $<\mathrm{MI}(\%)$ & $\mathrm{MI}(\%)$ & $\mathrm{MII}(\%)$ \\
\hline $6^{\mathrm{a}}$ & 45 & 97.8 & 2.2 & 0 \\
$12^{\mathrm{b}}$ & 55 & 23.6 & 76.4 & 0 \\
$18^{\mathrm{c}}$ & 50 & 2.0 & 34.0 & 64.0 \\
$24^{\mathrm{c}}$ & 47 & 2.1 & 19.1 & 78.8 \\
\hline
\end{tabular}

Conditions with different superscripts differ significantly (contingency table $-P<0.001$ ). $<\mathrm{MI}$, stages previous to metaphase I; MI, metaphase I; MII, metaphase II. Incubation was stopped and oocytes fixed and analyzed at the given times (in $\mathrm{hr}$ from the onset of the incubation period).

and normally matured oocytes $(\mathrm{n}=76): 70 \%$ and $83 \%$ MII for $3^{\prime}-\mathrm{dG}$ and normally matured, respectively $\left(\mathrm{X}^{2}: P>0.05\right)$.

Effects of the addition of $3^{\prime}$-dA at different times during maturation. Cyclin B1 poly(A) tail length and nuclear maturation status. Adding $3^{\prime}-$ $\mathrm{dA}$ to the incubation medium from $12 \mathrm{hr}$ or $18 \mathrm{hr}$ after the onset of the maturation period, resulted in oocytes showing at $24 \mathrm{hr}$ a smear length similar to control oocytes matured during $24 \mathrm{hr}$ in normal conditions. However, when $3^{\prime}$-dA was incorporated from $6 \mathrm{hr}$ of the beginning of the maturation period, an important shortening of the smear length was observed. The smear length equaled that of immature oocytes when 3 -dA was added at the onset of the culture period (Fig. 5).

Concerning nuclear maturation, none of the oocytes matured when $3^{\prime}$-dA was added at $6 \mathrm{hr}$. Addition of $3^{\prime}$-dA at $12 \mathrm{hr}$ blocked half of the oocytes at MI stage or before, the remaining half reaching the MII stage at the end of the maturation period. As most of the oocytes had already reached the MII stage by $18 \mathrm{hr}$ in our culture conditions, the addition of $3^{\prime}$-dA at $18 \mathrm{hr}$ had no effect on the rate of MII observed at $24 \mathrm{hr}$. Once more, $3^{\prime}-\mathrm{dG}$

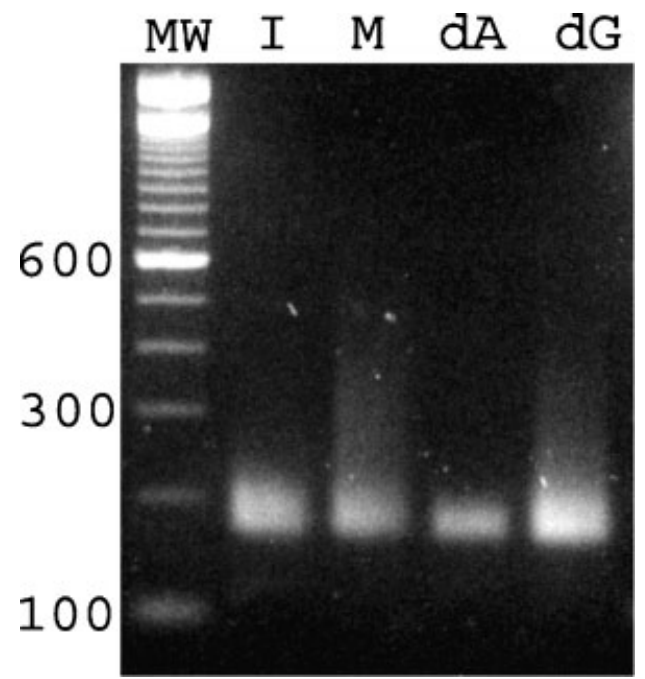

Fig. 4. RACE-PAT analysis of polyadenylation inhibition in cyclin B1 transcript, before and after maturation. MW: molecular weight marker (bp); I: immature oocytes; M: mature oocytes; dA: $0.02 \mathrm{mM} \mathrm{3'-}$ dA-treated oocytes; dG: $0.02 \mathrm{mM}$ 3'-dG-treated oocytes.

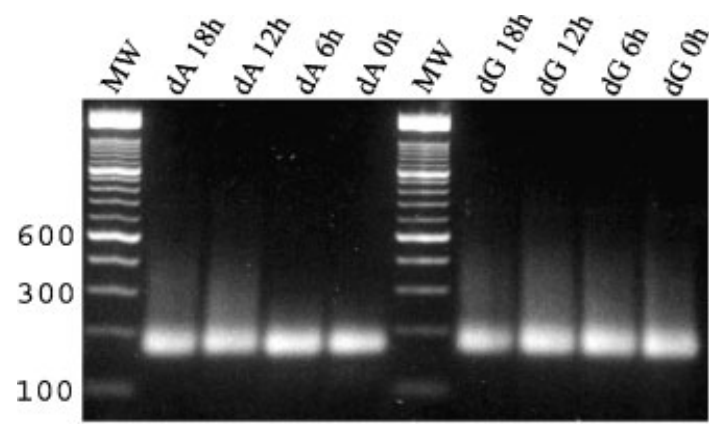

Fig. 5. RACE-PAT analysis in cyclin $B 1$ transcript, kinetics of polyadenylation inhibition. MW: molecular weight marker (bp); dA: $0.02 \mathrm{mM}$ 3'-dA-treated oocytes; dG: $0.02 \mathrm{mM} \mathrm{3'-dG-treated} \mathrm{oocytes.}$ Numbers indicate the time (in hours from the onset of the incubation) of addition of either 3 '-dA or dG. PCR analysis was done at $24 \mathrm{hr}$ for all treatments.

addition did not affect the smear length or the nuclear maturation rates in any of the groups observed (Fig. 6).

Study of the reversibility of the effect of $3^{\prime}$-dA on nuclear maturation status. In the conditions used in this study, adding $3^{\prime}$-dA during the first 4 or $6 \mathrm{hr}$ of maturation prevented oocyte maturation to the same extent as $24 \mathrm{hr}$ treatment with the same inhibitor. However, the addition of the polyadenylation inhibitor during the first $2 \mathrm{hr}$ of maturation, allowed $21 \%$ of the oocytes to reach MII stage (Table 2).

\section{DISCUSSION}

For the first time, the polyadenylation status of cyclin $\mathrm{A} 2$ and B1 mRNA was evaluated during IVM of bovine oocytes using RACE-PAT analysis.

Two sensitive PCR-based techniques allow to study the length of the poly(A) tail of specific transcripts: RACE-PAT, which we used in this work, and the ligasemediated polyadenylation technique (LM-PAT). LMPAT allows a more precise quantification of the poly(A) tail length, and was previously used to study the polyadenylation status of transcripts related to developmental competence in bovine oocytes (Brevini-Gandolfi et al., 1999; Brevini et al., 2002). Despite several

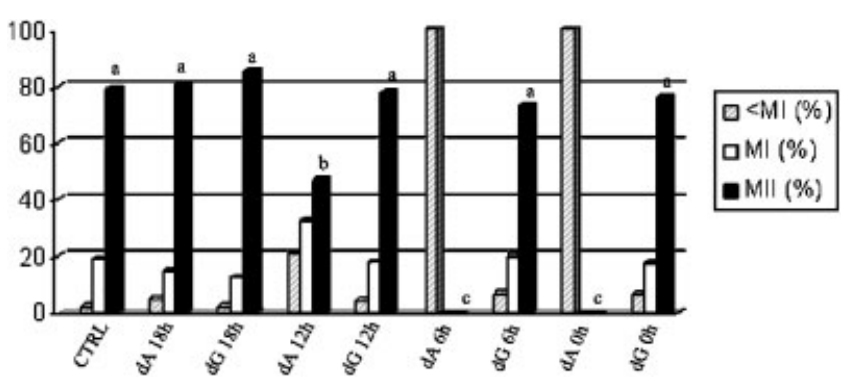

Fig. 6. Nuclear maturation kinetics in the presence of $3^{\prime}$-dA. CTRL control; dA: $0.02 \mathrm{mM}$ 3'-dA-treated oocytes; dG: $0.02 \mathrm{mM}$ 3'-dG-treated oocytes. Numbers indicate the time (in hours from the onset of the incubation) of addition of either $3^{\prime}$-dA or dG. Data with different superscripts are significantly different between groups (contingency table $-P<0.001$ ) 
TABLE 2. Test of Reversibility for the Action of $3^{\prime}$-dA

\begin{tabular}{llccc}
\hline Treatment & $\mathrm{N}$ & $<\mathrm{MI}(\%)$ & $\mathrm{MI}(\%)$ & $\mathrm{MII}(\%)$ \\
\hline Control $^{\mathrm{a}}$ & 56 & 0 & 19 & 81 \\
dA $24 \mathrm{hr}^{\mathrm{b}}$ & 54 & 100 & 0 & 0 \\
dG $24 \mathrm{hr}^{\mathrm{a}}$ & 49 & 0 & 16 & 84 \\
dA $2 \mathrm{hr}^{\mathrm{c}}$ & 47 & 32 & 47 & 21 \\
dG $2 \mathrm{hr}^{\mathrm{a}}$ & 54 & 5 & 15 & 80 \\
dA $4 \mathrm{hr}^{\mathrm{b}}$ & 50 & 96 & 0 & 4 \\
dG $4 \mathrm{hr}^{\mathrm{a}}$ & 57 & 7 & 18 & 75 \\
dA $6 \mathrm{hr}^{\mathrm{b}}$ & 59 & 100 & 0 & 0 \\
dG $6 \mathrm{hr}^{\mathrm{a}}$ & 41 & 7 & 15 & 78 \\
\hline
\end{tabular}

Data with different superscripts are significantly different (contingency table $-P<0.001$ ). $<\mathrm{MI}$, stages previous to metaphase I; MI, metaphase I; MII, metaphase II. Time in hr indicates the period of incubation with $3^{\prime}-\mathrm{dA} / \mathrm{dG}$, before washing and completing $24 \mathrm{hr}$ of incubation in normal maturation conditions.

essays, we did not succeed to obtain reproducible results using LM-PAT for cyclin A2 and B1 transcripts. A similar situation was reported by Fuchimoto et al. (2001), working with A1 and A2 cyclins in mouse oocytes.

Regarding cyclin A2 mRNA, an elongation of the smear was observed inconstantly within the different samples analyzed, which prevented us to study further the polyadenylation kinetics of this transcript. These variations could be due to the location of the $5^{\prime}$ primer used in the PCR amplification, which is not located as close to the poly(A) tail as it would be desirable to allow an easy detection of variations in the size of the amplicons. Unfortunately, due to the characteristics of the cyclin A2 sequence in the $3^{\prime}$ UTR, we did not succeed in finding better primers. Our results thus indicate that cyclin A2 transcripts are present in the bovine oocyte, but it is not clear whether their translation is regulated by cytoplasmic polyadenylation during IVM. This is in agreement with the results obtained in the mouse oocytes, where cyclin A2 transcripts are present at the GV stage, but the protein is only detected after fertilization (Fuchimoto et al., 2001). The expression of the protein in the mouse embryo is not related to the quantity of the mRNA (the highest levels of cyclin A2 mRNA are indeed observed at the GV stage), but to an increase in the size of the transcript observed after fertilization (Fuchimoto et al., 2001); and prevented by adding $3^{\prime}$-dA shortly after fertilization, which suggests that polyadenylation of the transcript plays a key role in the translation into the protein involved in the first mitosis. This period of early embryonic development was not the object of our study focused on bovine oocytes, but it could be interesting to evaluate in a further study the polyadenylation of cyclin A2 mRNA in the bovine embryo where, unlike the mouse, the major onset of the embryonic genome is not coincident with the first mitosis.

An important increase in the length of the smear was observed for cyclin B1 mRNA using two different primers. Such increase was associated with the lengthening of the poly(A)tail of the transcript during IVM as it disappeared in presence of $3^{\prime}-\mathrm{dA}$, an inhibitor of polyadenylation. It has been suggested that cyclin B1 synthesis plays a key role in meiotic resumption in bovine oocytes. Indeed, Levesque and Sirard (1996) demonstrated that, in this species, the injection of cyclin B1 was sufficient to trigger meiosis resumption in the presence of an inhibitor of protein synthesis. As summarized in the Introduction, cyclin B1 is one of the two components of the MPF. MPF presents two peaks of activity during oocyte nuclear maturation in vertebrates: the first one slightly preceding or coincident with MI, and the second with MII, with a temporary drop during the transition between MI and MII (reviewed by Nebreda and Ferby, 2000). This MPF activity pattern was also reported in the bovine by Wehrend and Meinecke (2001), Wu et al. (1997), and Fissore et al. (1996). Results obtained in the present work, allows us to postulate that cyclin B1 mRNA undergoes cytoplasmic polyadenylation between 0 and $12 \mathrm{hr}$ of maturation, and to a greater extent between 6 and $12 \mathrm{hr}$. This polyadenylation takes place in parallel with MPF activity, which starts around GVBD, and peaks around MI. In our culture conditions, most of the oocytes are in MI at $12 \mathrm{hr}$, and the poly(A) tail had also reached its maximal length by then. We can speculate that this poly(A) tail elongation would lead to a translation of the mRNA into cyclin B1 protein, accounting for the first peak in MPF activity in this species. In a short communication, Tremblay et al. (2004) showed some polyadenylation of bovine cyclin B1 already taking place before IVM, if the ovaries were transported and manipulated in warm saline. This polyadenylation was avoided if the transport and manipulation was performed on ice. Such changes in polyadenylation before the maturation period were not evaluated in this study.

Interestingly, the study by Tomek et al. (2002) in bovine oocytes reported that, if the incorporation of $\mathrm{A}$ residues was important between 2 and $6 \mathrm{hr}$, a further increase in incorporation took place between 6 and $10 \mathrm{hr}$ of maturation, when a drop in transcription activity was observed. This last observation strongly suggests that A residues are used for an intense polyadenylation process and not for transcription, which is in agreement with our results showing a major impact of polyadenylation inhibition at that time. Moreover, in this work, none of the oocytes reached the MI phase when polyadenylation was prevented by $3^{\prime}$-dA during the whole maturation period. Adding $3^{\prime}-\mathrm{dA}$ at $6 \mathrm{hr}$ after the onset of the maturation period (around the GVBD stage), also completely blocked meiotic progression, while addition from $12 \mathrm{hr}$ prevented only $30 \%$ of the oocytes to reach the MII stage. The fact that adding $3^{\prime}-\mathrm{dA}$ at $12 \mathrm{hr}$, around the MI stage, impaired nuclear maturation in only $30 \%$ of the oocytes suggested that polyadenylation processes are less critical for the transition between MI and MII than between GVBD and MI. Inhibition of polyadenylation from the MI stage had no impact on the polyadenylation of cyclin B1, and other target transcripts playing a role at later stages of nuclear maturation, are thus to be identified. 
The link between polyadenylation and the capacity to undergo nuclear maturation is further confirmed by the results obtained with the use of $3^{\prime}$-dG. When this purine analog was added to the maturation medium, neither polyadenylation nor nuclear maturation was affected, regardless of the duration, timing of addition or concentrations used (data not shown). This indicates that the inhibition of transcription arising from the use of this modified purine had no impact on nuclear maturation and that the effects observed using $3^{\prime}$-dA are clearly due to the inhibition of polyadenylation and not to transcription impairment that should occur with both purine analogs. Confirming evidence can be found in previous works (Farin and Yang, 1994; de Wit and Kruip, 2001; reviewed by Rodriguez and Farin, 2004), showing that bovine COCs are able to resume meiosis in vitro in the presence of transcription inhibitors, when FSH is not used in the maturation protocol.

The incubation with $0.02 \mathrm{mM} 3^{\prime}$-dA added to the maturation medium at $6 \mathrm{hr}$ or before led to an irreversible inhibition of meiosis resumption in all the oocytes. If $3^{\prime} \mathrm{dA}$ was added during the first $2 \mathrm{hr}$ of culture, an important drop in the maturation rate was observed after rinsing and restoring normal culture conditions. Nevertheless, $20 \%$ of the oocytes reached MII, and almost 50\% reached MI, showing that the inhibition was not always irreversible. The permanent effects observed could be due to the importance of the processes being affected by the action of $3^{\prime}-\mathrm{dA}$ at the beginning of the maturation period, like GVBD, and not necessarily to an irreversibility of the inhibition. Indeed, the reversibility of the action of $3^{\prime}$-dA has been extensively reported in the literature in somatic cells, as well as in Xenopus oocytes (Kuge and Inoue, 1992).

\section{CONCLUSIONS}

The variations in the polyadenylation status of cyclins A2 and B1 were studied for the first time during IVM in bovine oocytes. In parallel, the effects of polyadenylation inhibition on meiosis progression were also analyzed. We reported a poly(A) tail elongation for cyclin B1 transcript occurring during the first $12 \mathrm{hr}$ of IVM in bovine oocytes, which could account, at least partly, for the first MPF activity peak observed at the time of MI. Inhibition of polyadenylation and transcription prevented meiotic progression, especially when polyadenylation was blocked between GVBD and MI stages, while impairment of transcription alone never did.

\section{ACKNOWLEDGMENTS}

Technical assistance from Benjamin Verhaeghe and Joëlle Marchandise is greatly acknowledged.

\section{REFERENCES}

Barkoff A, Ballantyne S, Wickens M. 1998. Meiotic maturation in Xenopus requires polyadenylation of multiple mRNAs. EMBO J 17:3168-3175.

Brevini TAL, Lonergan P, Cillo F, Francisci C, Favetta LA, Fair T, Gandolfi F. 2002. Evolution of mRNA polyadenylation between oocyte maturation and first embryonic cleavage in cattle and its relation with developmental competence. Mol Reprod Dev 63:510517.

Brevini-Gandolfi TAL, Favetta LA, Mauri L, Luciano AM, Cillo F, Gandolfi F. 1999. Changes in poly(A) tail length of maternal transcripts during in vitro maturation of bovine oocytes and their relation with developmental competence. Mol Reprod Dev 52:427433.

de Moor CH, Richter JD. 1997. The Mos pathway regulates cytoplasmic polyadenylation in Xenopus oocytes. Mol Cell Biol 17:6419-6426.

de Moor CH, Richter JD. 2001. Translational control in vertebrate development. Int Rev Cytol 203:567-608.

de Wit AA, Kruip TA. 2001. Bovine cumulus-oocyte-complex-quality is reflected in sensitivity for alpha-amanitin, oocyte-diameter and developmental capacity. Anim Reprod Sci 65:51-65.

Farin CE, Yang L. 1994. Inhibition of germinal vesicle breakdown in bovine oocytes by 5,6-dichloro-1-beta-D-ribofuranosylbenzimidazole (DRB). Mol Reprod Dev 37:284-292.

Fissore RA, He CL, Vande Woude GF. 1996. Potential role of mitogenactivated protein kinase during meiosis resumption in bovine oocytes. Biol Reprod 55:1261-1270.

Fox CA, Sheets MD, Wickens MP. 1989. Poly(A) addition during maturation of frog oocytes: Distinct nuclear and cytoplasmic activities and regulation by the sequence UUUUUAU. Genes Dev 3:21512162.

Fuchimoto D, Mizukoshi A, Schultz RM, Sakai S, Aoki F. 2001. Posttranscriptional regulation of cyclin A1 and cyclin A2 during mouse oocyte meiotic maturation and preimplantation development. Biol Reprod 65:986-993.

Gebauer F, Richter JD. 1996. Mouse cytoplasmic polyadenylylation element binding protein: An evolutionarily conserved protein that interacts with the cytoplasmic polyadenylylation elements of c-mos mRNA. Proc Natl Acad Sci USA 93:14602-14607.

Gebauer F, Xu W, Cooper GM, Richter JD. 1994. Translational control by cytoplasmic polyadenylation of c-mos mRNA is necessary for oocyte maturation in the mouse. EMBO J 13:5712-5720.

Krischek C, Meinecke B. 2002. In vitro maturation of bovine oocytes requires polyadenylation of mRNAs coding proteins for chromatin condensation, spindle assembly, MPF and MAP kinase activation. Anim Reprod Sci 73:129-140.

Kuge H, Inoue A. 1992. Maturation of Xenopus laevis oocyte by progesterone requires poly(A) tail elongation of mRNA. Exp Cell Res 202:52-58.

Levesque JT, Sirard MA. 1996. Resumption of meiosis is initiated by the accumulation of cyclin B in bovine oocytes. Biol Reprod 55:14271436.

Lonergan P, Gutierrez-Adan A, Rizos D, Pintado B, de la Fuente J, Boland MP. 2003. Relative messenger RNA abundance in bovine oocytes collected in vitro or in vivo before and $20 \mathrm{hr}$ after the preovulatory luteinizing hormone surge. Mol Reprod Dev 66:297305.

Loyer P, Glaise D, Cariou S, Baffet G, Meijer L, Guguen-Guillouzo C. 1994. Expression and activation of cdks (1 and 2) and cyclins in the cell cycle progression during liver regeneration. J Biol Chem 269: $2491-2500$

Macdonald P. 2001. Diversity in translational regulation. Curr Opin Cell Biol 13:326-331.

Mangus DA, Evans MC, Jacobson A. 2003. Poly(A)-binding proteins: Multifunctional scaffolds for the post-transcriptional control of gene expression. Genome Biol 4:223. Epub 2003 Jul 01.

McGrew LL, Dworkin-Rastl E, Dworkin MB, Richter JD. 1989. Poly(A) elongation during Xenopus oocyte maturation is required for translational recruitment and is mediated by a short sequence element. Genes Dev 3:803-815

Memili E, First NL. 1999. Control of gene expression at the onset of bovine embryonic development. Biol Reprod 61:1198-1207.

Memili E, First NL. 2000. Zygotic and embryonic gene expression in cow: A review of timing and mechanisms of early gene expression as compared with other species. Zygote 8:87-96.

Morgan DO. 1995. Principles of CDK regulation. Nature 374:131134.

Murphy M, Stinnakre MG, Senamaud-Beaufort C, Winston NJ, Sweeney C, Kubelka M, Carrington M, Brechot C, Sobczak-Thepot J. 1997. Delayed early embryonic lethality following disruption of the 
murine cyclin A2 gene. Nat Genet 15:83-86. Erratum in: Nat Genet 1999;23:481.

Nakazato H, Edmonds M, Kopp DW. 1974. Differential metabolism of large and small poly(A) sequences in the heterogeneous nuclear RNA of HeLa cells. Proc Natl Acad Sci USA 71:200-204.

Nebreda AR, Ferby I. 2000. Regulation of the meiotic cell cycle in oocytes. Curr Opin Cell Biol 12:666-675.

Pagano M, Pepperkok R, Verde F, Ansorge W, Draetta G. 1992. Cyclin A is required at two points in the human cell cycle. EMBO J 11:961971.

Pincus G, Enzmann EV. 1935. The comparative behavior of mammalian eggs in vivo and in vitro. I. The activation of ovarian eggs. J Exp Med 62:655-675.

Richter JD. 1999. Cytoplasmic polyadenylation in development and beyond. Microbiol Mol Biol Rev 63:446-456.

Robert C, Hue I, McGraw S, Gagne D, Sirard MA. 2002. Quantification of cyclin B1 and p34(cdc2) in bovine cumulus-oocyte complexes and expression mapping of genes involved in the cell cycle by complementary DNA macroarrays. Biol Reprod 67:1456-1464.

Rodriguez KF, Farin CE. 2004. Gene transcription and regulation of oocyte maturation. Reprod Fertil Dev 16:55-67.

Salles FJ, Strickland S. 1995. Rapid and sensitive analysis of mRNA polyadenylation states by PCR. PCR Methods Appl 4:317-321.

Salles FJ, Richards WG, Strickland S. 1999. Assaying the polyadenylation state of mRNAs. Methods 17:38-45.

Sheets MD, Wu M, Wickens M. 1995. Polyadenylation of c-mos mRNA as a control point in Xenopus meiotic maturation. Nature 374:511516.

Siev M, Weinberg R, Penman S. 1969. The selective interruption of nucleolar RNA synthesis in HeLa cells by cordycepin. J Cell Biol $41: 510-520$
Smith LD. 1989. The induction of oocyte maturation: Transmembrane signaling events and regulation of the cell cycle. Development 107 685-699.

Stebbins-Boaz B, Hake LE, Richter JD. 1996. CPEB controls the cytoplasmic polyadenylation of cyclin, Cdk2 and c-mos mRNAs and is necessary for oocyte maturation in Xenopus. EMBO J 15:25822592.

Tay J, Hodgman R, Richter JD. 2000. The control of cyclin B1 mRNA translation during mouse oocyte maturation. Dev Biol 221:1-9.

Tomek W, Torner H, Kanitz W. 2002. Comparative analysis of protein synthesis, transcription and cytoplasmic polyadenylation of mRNA during maturation of bovine oocytes in vitro. Reprod Domest Anim 37:86-91

Tremblay K, Vigneault C, Bujold G, Sirard MA. 2004. Bovine oocyte cyclin B1 mRNA undergoes cytoplasmic polyadenylation before the beginning of in vitro maturation. Reprod Fertil Dev 16: 246.

Wasserman WJ, Masui Y. 1976. A cytoplasmic factor promoting oocyte maturation: Its extraction and preliminary characterization. Science 191:1266-1268.

Wehrend A, Meinecke B. 2001. Kinetics of meiotic progression, Mphase promoting factor (MPF) and mitogen-activated protein kinase (MAP kinase) activities during in vitro maturation of porcine and bovine oocytes: Species specific differences in the length of the meiotic stages. Anim Reprod Sci 66:175-184.

Wu B, Ignotz G, Currie WB, Yang X. 1997. Dynamics of maturationpromoting factor and its constituent proteins during in vitro maturation of bovine oocytes. Biol Reprod 56:253-259.

Yamashita M, Mita K, Yoshida N, Kondo T. 2000. Molecular mechanisms of the initiation of oocyte maturation: General and species-specific aspects. Prog Cell Cycle Res 4:115-129. 